\title{
Calculation Method Modification of Spare Parts Quantity to Restore Operability of Weapon Systems
}

\author{
P.V. Open'ko ${ }^{1 *}$, V.I. Mirnenko' ${ }^{1}$ V.V. Tyurin ${ }^{1}$, M.Yu. Myroniuk ${ }^{1}$, \\ O.M. Doska² and A.M. Bulay ${ }^{2}$ \\ ${ }^{1}$ Institute of Aviation and Air Defense, National Defense University of Ukraine named after \\ Ivan Cherniakhovskyi, Kyiv, Ukraine \\ ${ }^{2}$ Air Force Scientific Center, Ivan Kozhedub Kharkiv National Air Force University, \\ Kharkiv, Ukraine
}

\begin{abstract}
The manuscript was received on 19 January 2021 and was accepted after revision for publication as research paper on 31 May 2021.
\end{abstract}

\begin{abstract}
:
The article proposes a methodical approach to calculating the number of spare parts for weapon systems (WS) combat damage elimination and operability restoration based on criteria of minimization of spare parts cost, meeting the requirements of the spare parts, tools, supplies and materials, as well as timeliness of damaged WSs repair. The main points of the methodological approach (mathematical formalization of the task, basic calculation ratios, stages and order of calculation of spare parts stocks) are represented with a simplified scheme of the calculation of spare parts to ensure WS combat damage elimination and operability restoration. Probability of sufficiency and developed mathematical model for its calculation are used as a sufficiency indicator of spare parts to ensure WS combat damage elimination and operability restoration.
\end{abstract}

\section{Keywords:}

combat damage, maintenance, probability of spare parts sufficiency, repair, spare parts, weapon systems

\section{Introduction}

In wartime, combat damage of weapon systems (WS) affects or causes loss of the forces combat capability. Timely WS combat damage elimination and operability restoration requires the appropriate supply of spare parts, tools, supplies, and materials

\footnotetext{
* Corresponding author: Research Department of the Institute of Aviation and Air Defense, National Defense University of Ukraine named after Ivan Cherniakhovskyi, Povitroflotsky Prospect 28, UA-03049 Kyiv, Ukraine.Phone: +38066 76459 20, E-mail: pavel.openko@ukr.net. ORCID 0000-0001-7777-5101.
} 
(spare parts). The existing spare parts kits ensure WS maintenance and periodic maintenance. They eliminate operational failures and malfunction of service personnel (military repair bodies, field repair crews) $[1,2]$.

Combat damages mechanisms differ from misuse failures and significant deformations (holes) of WS housing, cabinets, chassis, power units, hydraulic and pneumatic drives, cable lines break and they influence the repair. Therefore, the approaches to the calculation of WS spare parts should take into account the following factors and requirements:

- random factors that cause combat damage of the WS components (type, quantity, technical characteristics, nature of ammunition action which is used against WS positions; characteristics of pointing and shooting (bombing) accuracy; constructive-functional features of WS construction, features of components allocation, geometric dimensions; characteristics of WS components resistance to adverse factors of ammunition, etc.),

- random and determining factors which define the capabilities of repair facilities to eliminate combat damage and renew the WS operation (strength of repair facilities, involved in the elimination of combat damage, personnel qualification, methods of elimination of combat damage, etc.) and

- requirements in terms of operability, reliability, and composition of repaired WS, time and cost requirements, etc.

Thus, while calculating the spare part kit, there is an immediate problem to predict future combat damage and corresponding stock of spare parts considering the above mentioned random and deterministic factors.

\section{Definition of Research Problem}

Spare parts and accessories as a reliability resource are very important in the design and maintenance of technical items. However, the reliability theory does not reflect sufficiently the problem of combat damage restoration with use of special spare parts kits. Today, there are a lot of studies related to problems of technical systems supply with spare parts [1-9].

In [1], we considered the issues of management of spare parts. A three-stage structure for multi-criteria classification of spare parts is proposed.

In [2], we considered method of calculation the number of spare parts under the condition of a known probability of repair of a technical system failed element. An expression for assessing the sufficiency indicator is presented.

In [3], we proposed the genetic algorithm for spare parts optimization. We demonstrated that in some cases the use of genetic algorithm permits to solve optimization tasks.

In [4], we considered two-tier system of spare parts supply. We proposed the method of spare parts distribution among customers. The proposed method is based on Poisson spare parts requests and on consideration of the distance between warehouse and customer, as well as spare parts stocks.

In [5], we considered methods permitting to solve complex systems reliability and maintenance multicriterial tasks. We presented the approach to select the most appropriate method for solving linear programming.

In [6], we considered the issues of spare parts management for multi-tier supply systems. The methods of spare parts optimization tasks were provided. The mathematical models of administration of low-demand expensive spare parts were proposed. 
In [7], we considered the procurement as spare parts replenishment. We developed the approach permitting to consider the spare parts cost to achieve their required quantity.

Models for solving the problem of spare parts management are presented in [8]. The proposed models are aimed at reducing the downtime of a product in an inoperative state and minimizing the cost of spare parts stocks, as well as their storage.

In [9], while calculating the composition of the spare parts kits we used the WS failure rate and combat damages rate which are common for extended operations. These operations are characterized by repeated combat damages and multiple restoration of the same WS spare part.

The damaged WSs are usually repaired by an aggregate method, such as replacement of damaged spare parts by good spare parts. The number of these repairs is unlimited. Therefore, the assumption of repeated damage and restoration of the same component does not fully correspond to the model of repair of damaged WS.

The reliability of the considered approaches [1-9] is defined by the reliability of calculation of failure and restoration rates, their approximation and assumptions, which are integrated, for example, into the Poisson flow. However, it is worth considering the fact that today the data on WS spare part damage and their restoration are limited, even absent. This fact prevents us from accurate evaluation of spare parts combat damage and their restoration rate.

Thus, the use of the existing approaches [1-9] to determine the composition of spare parts designed to eliminate combat damage and restore the WS operability is inappropriate, and the topic of the article is relevant.

The purpose of the article is to develop a calculation method modification of spare parts quantity to restore WS operability to solve the problem of combat damage elimination and restoration of WS operability using the criterion of minimizing the cost of spare parts while meeting the requirements for sufficiency indicators of spare parts kits, tools, supplies and materials and the timely repair of damaged WS.

\section{Description of the Method and Basic Mathematical Equations}

The technology of damaged WS repair means defecting, combat damages elimination and their operability restoration. Elimination of combat damages and restoration of WS operability is usually ensured by replacement of damaged spare parts at different indenture level (items, cabinets, blocks, assemblies, parts) [9].

The higher the indenture level, the less time spent on WS repair. On the other hand, in case of unreasonably high indenture level, the price of spare parts kit grows considerably. Moreover, the current stable trend to reduce repair time means the appropriate use of spare parts of higher indenture level. Therefore, the nomenclature of spare parts used for WS combat damage elimination and operability restoration differs from the nomenclature of spare parts kits use. Particularly, such spare parts kits are used for block structure with a possibility to detect operational malfunctions at the level of functional assemblies.

The purpose of the formation of such spare parts kits is to ensure timely repairs of damaged WS. This possibility is not guaranteed to be achievable due to the random composition of the damaged WS components and the limited spare parts. Therefore, as an indicator of the adequacy of spare parts for spare parts kits, the probability of sufficiency is used. 
The probability of spare parts could be understood as the probability that the spare parts will provide appropriate repair of the WS without failure for the available time.

The failure of spare parts means the condition when the WS was damaged and became inoperable, and the spare part kits cannot provide the necessary spare parts for repair.

Then the task of calculating the composition of spare parts for spare parts kits to ensure the elimination of combat damage and recovery of weapons is to find such a range and number of spare parts, the total cost of which is minimal, and the restrictions are met:

- the probability of sufficiency of spare parts must be at least the specified value $P_{\mathrm{sp}}^{r}$,

- the number of spare parts of each nomenclature is a positive integer $Z_{+}$

$$
\begin{gathered}
C(X *)=\min \sum_{f=1}^{\xi} \sum_{\ell=1}^{\theta_{f}} c_{f \ell} x_{f \ell} \\
P_{\mathrm{sp}}\left(X, t_{r}\right) \geq P_{\mathrm{sp}}^{r} \\
x_{f \ell} \in Z_{+}
\end{gathered}
$$

where $C\left(X^{*}\right)$ - the total cost of spare parts, $\xi$ - the number of indenture levels of components, that ensure the WS operability, $\theta_{f}$ - the number of types of components, $f$-th indenture level that ensure the WS operability, $c_{f \ell}$ - the cost of the spare part $\ell$-th type $f$-th indenture level, $x_{f \ell}$ - the number of spare parts of the $\ell$-th type $f$-th indenture level, $P_{\mathrm{sp}}\left(X, t_{r}\right)$ - the probability that the spare parts will be sufficient for damage elimination and restoration of the WS operability in time, $P_{\mathrm{sp}}^{r}-$ the required value of the probability that the spare parts will be sufficient for damage elimination and restoration of the WS operability.

The statement of the task of calculating the composition of spare parts to ensure the elimination of combat damage and the restoration of the WS operability during higher complexity repairs (medium maintenance) is the same as for less complexity repairs (periodic maintenance). The exception is that while determining the number of spare parts, the strength of the repair facilities involved in carrying out the appropriate repairs is taken into account, and in limitation (2), the required value $P_{\mathrm{sp}}^{r}$ is calculated based on the time available for such repairs.

The use of spare parts for the intended purpose can be effective if, at the same time, they do not fail and will provide appropriate repairs within the time available. The probability of such an occasion can be found as the probability of a complex event:

$$
P_{\mathrm{sp}}\left(X, t_{r}\right)=P_{\mathrm{sp}}(X) P\left(t_{r} / X\right)
$$

where $P_{\mathrm{sp}}(X)$ - the probability that the spare parts will be sufficient for WS repair, $P\left(t_{r} / X\right)$ - the conditional probability of repair for a time not exceeding the set value, under the condition that the spare parts are sufficient.

The conditional probability depends on the time required for the repair and can be estimated by the ratio: 


$$
P\left(t_{\mathrm{r}} / X\right)=1-\exp \left(-\frac{t_{r}}{T_{x}}\right)
$$

where $T_{x}$ - the expected repair time of damaged WS using $x$-th spare parts kit.

For determination $P_{\mathrm{sp}}(X)$, we suppose that the number $n$ and structure of damaged WS is known and that its components are damaged independently of one another. Each component of $\ell$-th type $f$-level that is part of WS may be damaged with probability $P_{f \ell}$ or not damaged with probability $q_{f \ell}=1-P_{f \ell}$. In addition, there is a probability of damage of spare parts in the spare parts kits. Therefore, we introduce: $P_{f \ell}^{\mathrm{sp}}-$ the probability of combat damage of a spare part of $\ell$-th type $f$-level of indenture in the spare parts kits, the probability of the opposite occasion is equal to $q_{f \ell}^{\mathrm{sp}}=1-P_{f \ell}^{\mathrm{sp}}$.

We propose to consider the case where the WS and the spare parts kit include components and spare parts of the same nomenclature, and then we get a calculated ratio, taking into account that the WS and the spare parts kit consist of components and spare parts of different nomenclature $\left(f=\overline{1, \xi}, \ell=\overline{1, \theta_{f}}\right)$.

We introduce the structure of the components of the $\ell$-th type $f$-th level of the WS and corresponding spare parts to it in the form of a structural diagram of the reliability of the system "product-spare parts" with sliding redundancy (Fig. 1).

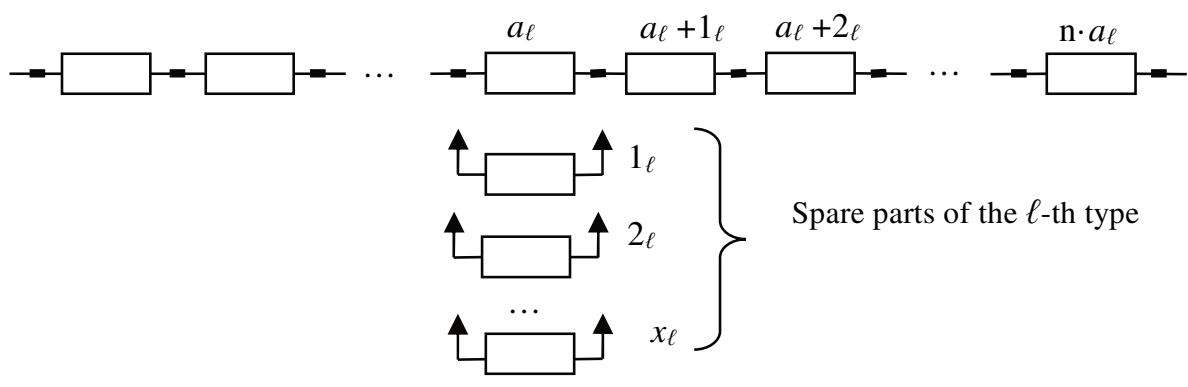

Fig. 1 Structural diagram of the reliability of the "product-spare parts" system with sliding redundancy

Then the occasion $A_{f, \ell}$ which is that the "product-spare parts" system will lose its capacity to work when the number of spare elements is insufficient to meet the need to replace the main components of the $\ell$-th type $f$-th level of indenture.

In the normal case, when the probabilities of combat damage of components and spare parts of the $\ell$-th type $f$-th level of indenture are different, the technical condition of the "product-spare parts" system can be described as follows:

$$
\phi_{f \ell}(z)=\left[\prod_{j=1}^{n a_{f \ell}}\left(q_{f, \ell, j}+P_{f, \ell, j} z\right)\right] \cdot\left[\prod_{j=n a_{f \ell}}^{n a_{f \ell}+x_{f \ell}}\left(q_{f, \ell, j}^{\mathrm{sp}}+P_{f, \ell, j}^{\mathrm{sp}} z\right)\right]
$$

where $\varphi_{f \ell}(z)$ - the generating function that characterizes the technical condition of components and spare parts of the $\ell$-th type $f$-th level of indenture of the "productspare parts", $n$ - the number of damaged WSs, $z$ - an arbitrary parameter of a generic function.

According to the theory of repetition of experiments [10], the probability that the system "product-spare parts" will lose its efficiency due to combat damage is $k$ to the 
component parts, is equal to the coefficient $z^{k}$ when expressing the generating function, then expression (6) takes the form:

$$
\left[\prod_{j=1}^{n a_{f \ell}}\left(q_{f, \ell, j}+P_{f, \ell, j} z\right)\right] \cdot\left[\prod_{j=n a_{f \ell}}^{n a_{f \ell}+x_{f \ell}}\left(q_{f, \ell, j}^{\mathrm{sp}}+P_{f, \ell, j}^{\mathrm{sp}} z\right)\right]=\sum_{k=0}^{N_{f \ell}} P_{f, \ell, k} z^{k}
$$

where $P_{f, \ell . k}$ - the probability of loss of performance of the system "product-spare parts" due to combat damage equal to components of the $\ell$-th type $f$-th level of unbundling; $N_{f \ell}$ - the total number of components and spare parts of the $\ell$-th type $f$-th level of indenture in the system "product-spare parts".

Then the probability of occurrence of the event can be calculated by the relation:

$$
P\left(A_{f, \ell}\right)=\sum_{k=x_{f, \ell}+1}^{N_{f \ell}} P_{f, \ell, k}
$$

where $P\left(A_{f, \ell}\right)$ - the probability that the system "product-spare parts" will lose its efficiency, $x_{f \ell}$ - the number of spare parts of the $\ell$-th type $f$-th level of indenture in the system "product-spare parts".

Considering Eqs (8) and (5) we have:

$$
P_{\mathrm{sp}}\left(x_{f \ell}, t_{r}\right)=\left[1-\sum_{k=x_{f, \ell}+1}^{N_{f \ell}} P_{f, \ell, k}\right] \times\left[1-\exp \left(-\frac{t_{r}}{T_{f \ell}}\right)\right]
$$

where $P_{\mathrm{sp}}\left(x_{f, \ell}\right)$ - the probability of sufficiency of spare parts of the $\ell$-th type $f$-th level of indenture, $T_{f \ell}$ - the expected repair time of damaged WS using spare parts of the $\ell$-th type $f$-th level of indenture.

Then $P_{\mathrm{sp}}\left(X, t_{r}\right)$ can be calculated by the ratio:

$$
P_{\mathrm{sp}}\left(X, t_{r}\right)=\prod_{f=1}^{\xi} \prod_{\ell=1}^{\theta_{f}} P_{\mathrm{sp}}\left(x_{f \ell}, t_{r}\right)
$$

Therefore, the formulated problem (1)-(3) can be solved as follows (Fig. 2). In the first stage, for each WS component, starting from the highest indenture level, the possibility of its replacement by a spare part is checked, with further control of efficiency, followed by the control of working capacity using regular repair means, control and measuring equipment, repair units involved in the repair (block 4).

If it is not possible to replace the selected component with a spare part by repair units, the decision to dismantle it is made and its possibility of repair is considered by replacing the damaged components of the lower level of the hierarchy (blocks 10, 11). If the unbundling of the WS component does not give a positive result, a decision is made to carry out remedial repairs of a higher level of complexity (block 14).

In the second stage, the optimization problem (block 8) is solved. In this case, it is proposed to use a sequential optimization algorithm [2].

The algorithm is as follows (Fig. 3):

- we assign the initial value of the number of spare parts of each type of nominal zero $x_{f \ell}=0 ; f=\overline{1, \xi ; \ell}=\overline{1, \theta_{f}}$ (block 2 ),

- consistently for all types of spare parts $f=\overline{1, \xi}$; $\ell=\overline{1, \theta_{f}}$, we calculate the probability of their sufficiency, provided that $x_{f \ell}=0$ (blocks 3-5), 
- we calculate the probability of sufficiency of the spare parts kit as a whole (block 6) $P_{\mathrm{sp}}\left(X, t_{r}\right)$,

- we check that condition (2) (block 7) is met.

If condition (2) is not fulfilled, at each iteration, we add one spare part of the $\ell$-th type $f$-th level of unbundling (block 11) to the initial composition of the spare part kit. The type of spare parts for which $\delta_{f e}$ is maximum is selected (block 9-10):

$$
\delta_{f \ell}=\max \left(\frac{\left|P_{\mathrm{sp}}\left(k_{f \ell}\right)-P_{\mathrm{sp}}\left(k_{f \ell}+1\right)\right|}{c_{f \ell}}\right) ; f=\overline{1, \xi} ; \ell=\overline{1, \theta_{f}}
$$

where $\delta_{f \ell}$ - a relative decrease of sufficiency indicator of the spare part of the $\ell$-th type $f$-th level of indenture per unit of cost, $P_{\mathrm{sp}}\left(k_{f \ell}\right)$ - the probability of sufficiency of spare parts of the $\ell$-th type $f$-th level of indenture of the WS, $k_{f \ell}$ - the number of spare parts of the $\ell$-th type $f$-th level of indenture, $c_{f \ell}$ - the cost of the spare part of the $\ell$-th type $f$ th level of indenture.

For a new number of spare parts, the sufficiency indicator is calculated and the condition (2) is checked. The procedure is repeated until condition (2) is fulfilled. Thus, the composition of spare parts is formed to ensure the combat damage elimination and restoration of the WS operability, the cost of which is minimal, and restrictions on the adequacy of the spare parts kit and timeliness of repair are fulfilled. Based on the results of the calculations, the data of the spare parts are issued.

The efficiency of the developed method will be tested on a hypothetical component of the WS. The functional scheme of the hypothetical component of the WS is presented in Fig. 4.

Assuming that the WS components and spare parts presented in the Fig. 4 received combat damage, then any component damage breaks the WS working condition. The structural scheme of reliability "product-spare parts" for any component is a series connection of elements with sliding redundancy (Fig. 1).

WS combat damage elimination and operability restoration are provided by the aggregate method to replace the damaged components with spare parts, followed by a comprehensive setup of the equipment. Requirements for the time of repair and spare parts sufficiency are set and are as follows: $t_{r}=2$ hours, $P_{\mathrm{sp}}=0.92$.

Examples of presentation of the initial data and the results of calculating the spare parts number of the hypothetical element of the WS are given in Tabs 1-3.

The initial data for real WS can be obtained from the statistics of the results of combat damage or from the data of forecasting using a known mathematical apparatus [9].

Thus, the composition of spare parts is formed to ensure WS combat damage elimination and operability restoration, the cost of which is minimal, and restrictions on the adequacy of the spare parts kit and timeliness of repair are fulfilled. 


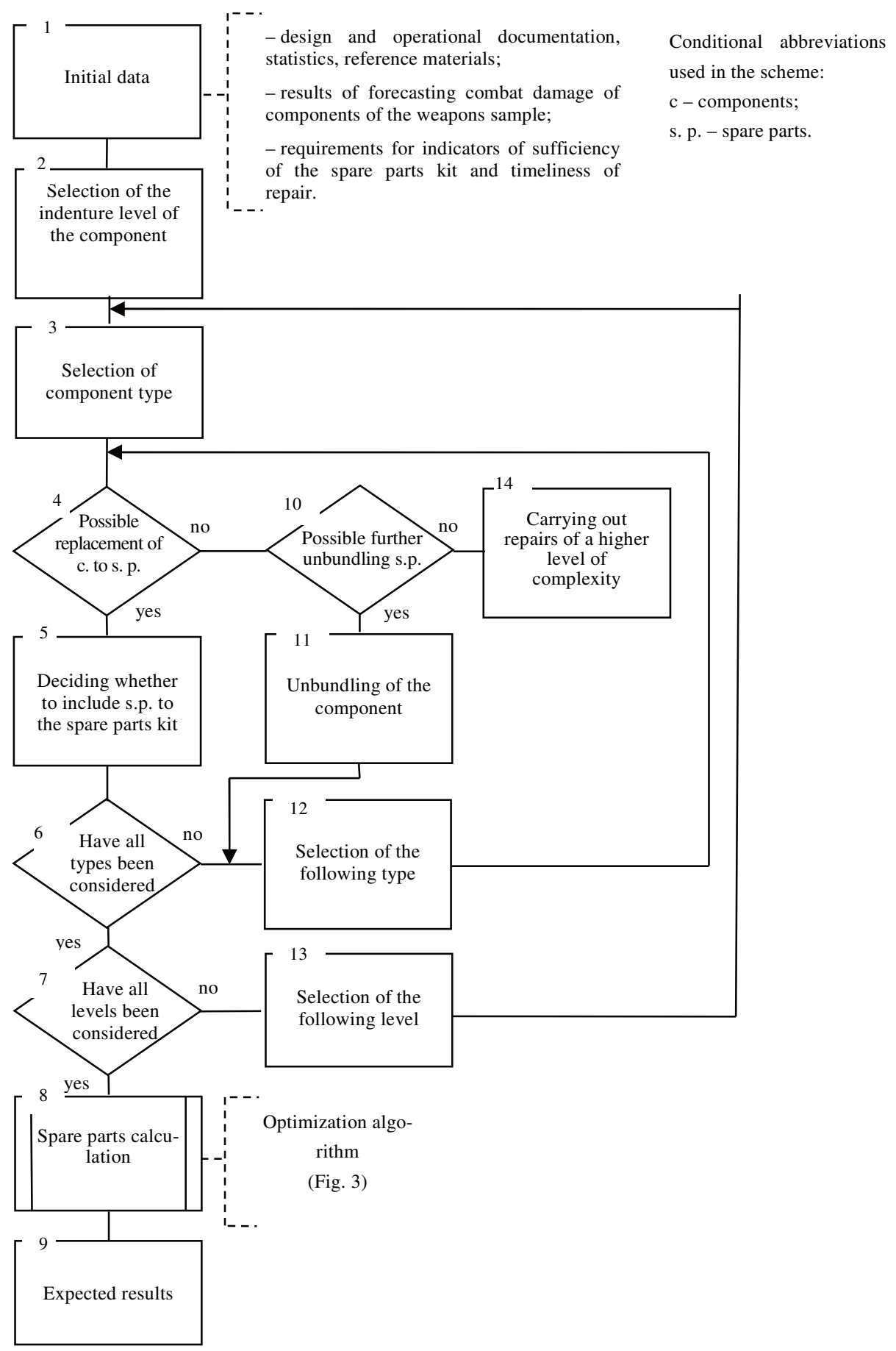

Fig. 2 Simplified scheme for calculating composition of spare parts to ensure combat damage elimination and restoration of WS operability 


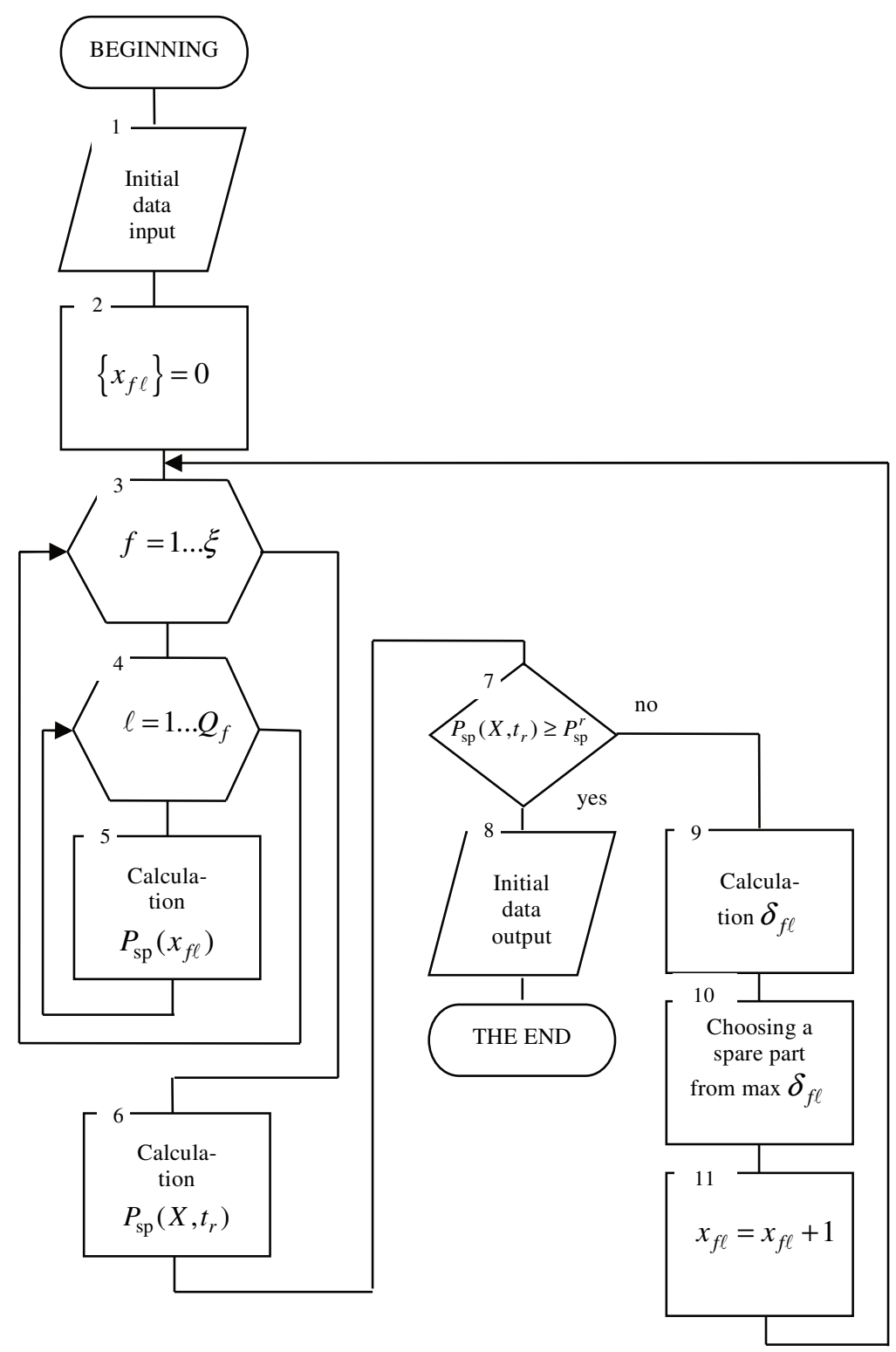

Fig. 3 Simplified scheme of a sequential algorithm for optimizing composition of spare parts to ensure combat damage elimination and restoration of WS operability 


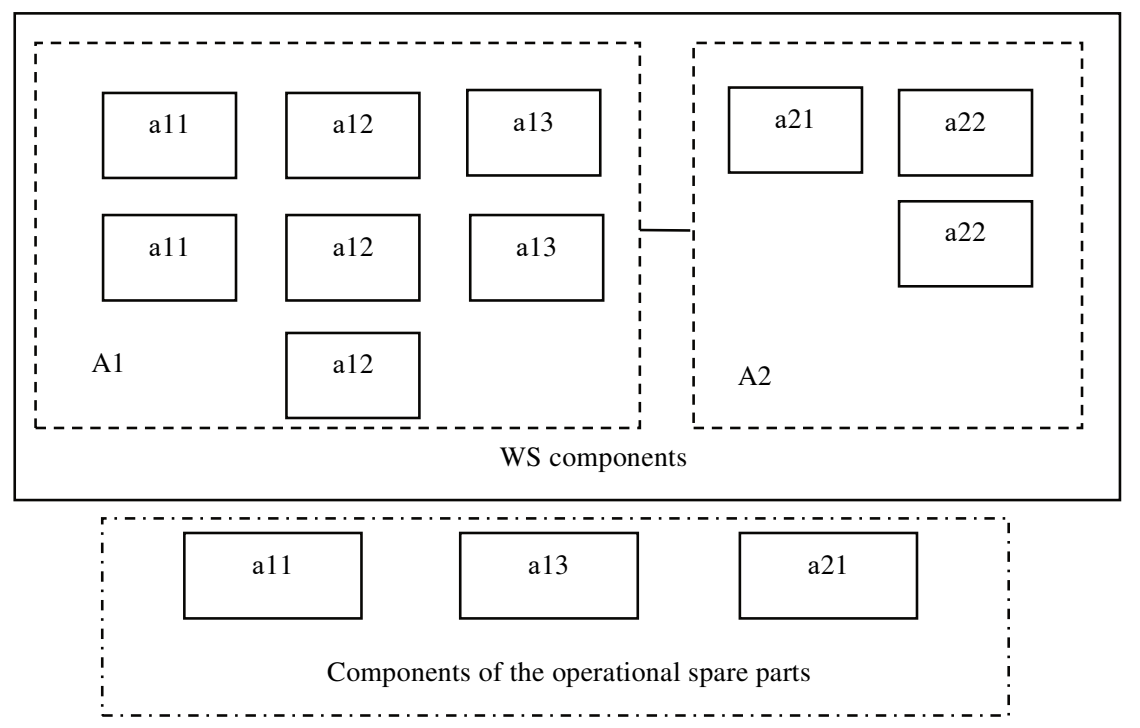

Fig. 4 Functional scheme of hypothetical component of WS

Tab. 1 Initial data for calculation of spare parts

\begin{tabular}{|c|c|c|c|c|c|c|c|c|}
\hline \multirow[b]{2}{*}{ № } & \multirow{2}{*}{ 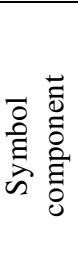 } & \multirow{2}{*}{ 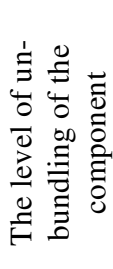 } & \multicolumn{2}{|c|}{$\begin{array}{l}\text { Number of } \\
\text { components }\end{array}$} & \multicolumn{2}{|c|}{$\begin{array}{c}\text { Probability of combat } \\
\text { damage component }\end{array}$} & \multirow{2}{*}{ 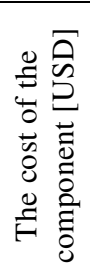 } & \multirow{2}{*}{ 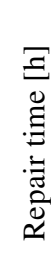 } \\
\hline & & & in the WS & $\begin{array}{l}\text { in a spare } \\
\text { parts kit }\end{array}$ & in the WS & $\begin{array}{l}\text { included with } \\
\text { spare parts }\end{array}$ & & \\
\hline 1 & A1 & I & 1 & - & 0.52 & - & 250 & 2.5 \\
\hline 2 & a11 & II & 2 & 1 & 0.07 & 0.02 & 20 & 0.5 \\
\hline 3 & a12 & II & 3 & - & 0.12 & - & 15 & 0.3 \\
\hline 4 & a13 & II & 2 & 1 & 0.28 & 0.025 & 10 & 0.5 \\
\hline 5 & $\mathrm{~A} 2$ & $\mathrm{I}$ & 1 & - & 0.36 & - & 200 & 2.0 \\
\hline 6 & a21 & II & 1 & 1 & 0.17 & 0.01 & 25 & 0.4 \\
\hline 7 & a22 & II & 2 & - & 0.08 & - & 7 & 0.5 \\
\hline
\end{tabular}

\section{Conclusions}

Thus, a sufficiency indicator of spare parts is suggested to provide the WS combat damage elimination and operability restoration - the sufficiency probability. Its concept was specified and the mathematical model of its calculation was developed, which, in contrast to the existing ones, takes into account the possibility of combat damage to both components and spare parts, as well as time constraints on repairing damaged equipment. The developed model is based on one-time applications for spare parts and their one-time restoration, which allows eliminating assumptions about the spare parts requests flow rate and their recovery rate and, accordingly, increases the reliability of the calculation. 
Tab. 2 Probability results of spare parts sufficiency assessment

\begin{tabular}{|c|c|c|c|c|c|c|c|c|}
\hline \multirow{3}{*}{ № } & \multirow{3}{*}{ 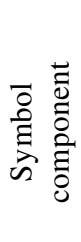 } & \multicolumn{4}{|c|}{$\begin{array}{c}\text { Probabilities of spare parts } \\
\text { sufficiency }\end{array}$} & \multicolumn{3}{|c|}{$\begin{array}{l}\text { Relative reduction of the adequacy } \\
\text { rate per unit of cost } \delta_{f \ell}\end{array}$} \\
\hline & & \multicolumn{7}{|c|}{ Number of spare parts $x_{f \ell}$} \\
\hline & & 0 & 1 & 2 & 3 & 1 & 2 & 3 \\
\hline 1 & A1 & 0.48 & 1 & - & - & $2.08 \times 10^{-3}$ & - & - \\
\hline 2 & a11 & 0.8476 & 0.9924 & 0.9999 & 1 & $7.24 \times 10^{-3}$ & $3.75 \times 10^{-4}$ & $0.5 \times 10^{-5}$ \\
\hline 3 & a12 & 0.6815 & 0.9603 & 0.9983 & 1 & $18.58 \times 10^{-3}$ & $25.33 \times 10^{-4}$ & $11.3 \times 10^{-5}$ \\
\hline 4 & a13 & 0.5054 & 0.9115 & 0.9980 & 1 & $40.60 \times 10^{-3}$ & $86.50 \times 10^{-4}$ & $20.0 \times 10^{-5}$ \\
\hline 5 & $\mathrm{~A} 2$ & 0.64 & 1 & - & - & $3.00 \times 10^{-3}$ & - & - \\
\hline 6 & a21 & 0.8217 & 0.9983 & 1 & - & $7.00 \times 10^{-3}$ & $0.68 \times 10^{-4}$ & - \\
\hline 7 & a22 & 0.8464 & 0.9936 & 1 & - & $21.00 \times 10^{-3}$ & $9.14 \times 10^{-4}$ & - \\
\hline
\end{tabular}

Tab. 3 Spare parts number assessment results

\begin{tabular}{|c|c|c|c|c|}
\hline № & $\begin{array}{c}\text { Symbol of } \\
\text { spare } \\
\text { parts }\end{array}$ & $\begin{array}{c}\text { Number of } \\
\text { spare parts } \\
x_{f e}\end{array}$ & $\begin{array}{c}\text { Spare parts } \\
\text { sufficiency prob- } \\
\text { ability taking into } \\
\text { account } \\
\text { repair time }\end{array}$ & $\begin{array}{c}\text { The spare } \\
\text { parts total } \\
\text { cost, } \\
\text { USD }\end{array}$ \\
\hline 1 & A1 & 0 & & \\
\hline 2 & a11 & 1 & \multirow{2}{*}{0.9204} & \multirow{2}{*}{102} \\
\hline 3 & a12 & 2 & \\
\hline 4 & a13 & 2 & \\
\hline 5 & A2 & 0 & & \\
\hline 6 & a21 & 1 & & \\
\hline 7 & a22 & 1 & \\
\hline
\end{tabular}

We have proposed the methodological approach to the calculation of the number of spare parts to eliminate the WS combat damages and restore operability. It is based on formalization of optimizational task of calculation of spare parts and its solving procedure. A method for calculating the number of spare parts has been developed to ensure the WS combat damage elimination and operability restoration. It includes the formalization of problem optimization of the spare parts composition calculation and the procedure of its resolution. The methodological approach includes the use of the criterion of minimization of the cost of spare parts in line with meeting requirements to indicators of sufficiency of spare parts kits and opportune repair of the damaged WS.

In addition, when determining the nomenclature of spare parts, the capabilities of repair units to eliminate combat damage and restore the WS operability are taken into account. 


\section{References}

[1] HU, Q., S. CHAKHAR, S. SIRAJ and A. LABIB. Spare Parts Classification in Industrial Manufacturing Using the Dominance-based Rough Set Approach. European Journal of Operational Research, 2017, 262(3), pp. 1136-1163. DOI 10.1016/j.ejor.2017.04.040.

[2] YIN, Z., F. Lin, Y.F. GUO and M.S. LAI. Calculation of Quantities of Spare Parts and the Estimation of Availability in the Repaired as Old Models. In: Tan Y., Y. Shi, Y. Chai, G. Wang (eds) Advances in Swarm Intelligence. Part II. ICSI 2011. LNCS 6729. Berlin: Springer, 2011, pp. 419-426. DOI 10.1007/978-3-64221524-7_51.

[3] PAN, G., Q. LUO, X. LI, Y. WANG and C. HUANG. Model of Spare Parts Optimization Based on GA for Equipment. In: Proceedings of the $20183^{\text {rd }}$ International Conference on Modelling, Simulation and Applied Mathematics. Shanghai: Atlantis Press, 2018, pp. 44-47. ISBN 978-9-46-252566-5.

[4] KUTANOGLU, E. and M. MAHAJAN. An Inventory Sharing and Allocation Method for a Multi-Location Service Parts Logistics Network with Time-Based Service Levels. European Journal of Operational Research, 2009, 194(3), pp. 728-742. DOI 10.1016/j.ejor.2007.12.032.

[5] AlmeidA, A.T. de, C.A.V. CAVAlCANTE, M.H. ALENCAR, R.J.P. FERREIRA, A.T. de ALMEIDA-FILHO and T.V. GARCEZ. Multicriteria and Multiobjective Models for Risk, Reliability and Maintenance Decision Analysis. New York: Springer, 2015. ISBN 978-3-31-917968-1.

[6] MUCKSTADT, J.A. Analysis and Algorithms for Service Parts Supply Chains. New York: Springer, 2005. ISBN 978-0-38-722715-3.

[7] RUSTENBURG, W.D., G.-J. van HOUTUM and W.H.M. ZIJM. Spare Parts Management for Technical Systems: Resupply of Spare Parts under Limited Budgets. IIE Transactions, 2000, 32(10), pp. 1013-1026. DOI 10.1080/07408170008967458.

[8] GU, J., G. ZHANG and K.W. LI. Efficient Aircraft Spare Parts Inventory Management under Demand Uncertainty. Journal of Air Transport Management, 2015, 42, pp. 101-109. DOI 10.1016/j.jairtraman.2014.09.006.

[9] BOYARNYKOV, V.B. Restoration of Military and Combat Equipment of AntiAircraft Missile Troops Country's Air Defence (in Russian). Minsk: MVZRU PVO, 1972.

[10] ASH, R.B. Basic Probability Theory. New York: Dover Publications, 2008. ISBN 978-0-48-646628-6. 